\title{
Experimental Investigations of Damping in Multilayered Materials
}

\author{
Odon Musimbi, $\mathrm{PhD}^{1}$; Julio Proano, $\mathrm{PhD}^{2}$ \\ 1,2Metropolitan State University of Denver, USA, omusimbi@msudenver.edu, jproano@msudenver.edu
}

\begin{abstract}
Damping characteristic of a material, also known as loss factor in dynamics, is challenging to estimate. However, the accurate determination of the damping value is critical in the prediction of vibration response and in the control of structural vibrations. While many studies have focused on the accurate measurement of the loss factor and other dynamic characteristics, there is a need for the study of factors controlling the damping and its variation. This work seeks to understand the variation of damping at a given point in a material and across the length and depth of material. The approach uses the time domain and a single frequency mode in all the configurations during the study. Different layered arrangements of composite beams are considered to study the influence of the layer configuration in the overall dynamic response. The study finds substantial damping variation at a single point, along the length of the samples and very little variation along the depth or thickness of the samples. The research also highlights the importance of the layers arrangements with the overlaying top layers materials governing the overall damping response of the layers.
\end{abstract}

Keywords-- Damping, Cyclic loading, layers, Vibrations, Dynamics

\section{INTRODUCTION}

Damping is a dynamic characteristic of materials that is challenging to determine [1]. The challenge in estimating the damping of a material stems from the fact that this characteristic is both a measure of the loss of energy in unbound medium- known as radiation damping -and a measure of the hysteretic behavior of materials under cyclic loading also known as material damping [2]. However, the accurate determination of the damping value is critical in the prediction of vibration response and in the control of structural vibrations. In a different field, damping has also been used to model shocks in financial markets [3]. With the development of new materials in airplanes, cars, rails and ships, the solution in noise control and vibrations in multilayered plates under dynamic loading requires not only a correct determination of the damping values of these materials but also a correct understanding of the factors governing the overall damping of these layered materials. Many authors have conducted experiments leading to the measurement of damping factors [4-6].

A significant contribution in the experimental determination of the loss factor in layered materials is due to Oberst [7]. Using a multilayered beam, Oberst established the equations of free layer damping and characterized damping in multilayered beams [8]. Oberst's beam method (OBM) has given birth to the development of standards E756-03 [9, 10] used in the accurate determination of damping values of material. Koruk and Sanliturk [8] provided comprehensive details on how to apply Oberst's procedures and perform the exact measurement of the damping characteristic. In particular, the boundary conditions, the sample size, the electromagnetic loading for the excitation and the noncontacting sensors reading the output from the beams are the required conditions to meet for proper damping measurement.

Oberst's approach uses the Frequency Response Function (FRF) of a bare beam and compares it to the FRF of the damped beam to determine the loss factor as well as the frequency dependent elastic modulus. In the class of identification problems, where the vibratory input and output are known and the material characteristics unknown, more work has been performed in the frequency domain $[11,12]$ while less work exist in the time domain [11]. Simpler methods in time domain have been developed to compute the parameters needed in characterization of the dynamic response of structures, namely the damping ratio and the elastic modulus. While Oberst and subsequent work has been primarily focused on the determination of the exact values of the dynamic characteristics, the lack of simplicity and the stringent protocols to follow make it difficult to apply outside the laboratory. Hence, the need for faster and simpler methods providing quicker and reasonably accurate damping factor measurements.

Ciornei et al. [13] determined damping and elastic moduli of clamped free-end wood samples using the logarithmic decrement of the displacement. In the study, the beams were clamped and excited with an initial displacement. The damping of the material was calculated by means of the logarithmic decrement of the recorded response. This study led to values of dynamic characteristics of acceptable accuracy.

While these studies have focused on the accurate measurement of the loss factor and other dynamic characteristics, the factors controlling damping were not covered. Questions remaining include how damping varies. What factors contribute to the reduction of damping in multilayered configurations? What arrangement of layers will provide the desired outcome of damping in any given application? Answers to these questions will provide insights to the designers in the effort to produce the desired outputs of dynamic characteristics.

This work deals with the variation of damping at a given point in a material and across the length and depth of material. Time domain and a single frequency mode are

Digital Object Identifier (DOI):

http://dx.doi.org/10.18687/LACCEI2019.1.1.97

ISBN: 978-0-9993443-6-1 ISSN: 2414-6390

$17^{\text {th }}$ LACCEI International Multi-Conference for Engineering, Education, and Technology: "Industry, Innovation, And Infrastructure for Sustainable Cities and Communities", 24-26 July 2019, Jamaica. 
used in all the configurations within the study. Different layered arrangements of composite beams are considered to study the influence of the layer configuration in the overall dynamic response. The study finds substantial damping variation along the length of the samples and very little variation along the depth or thickness of the samples. The research also highlights the importance of the layers arrangements with overlaying top layers materials governing the overall damping response of the layers.

\section{THEORETICAL BACKGROUND}

For a load $\mathrm{P}$ applied to cantilever beam shown in Figure 1 and released, the beam will undergo a damped vibratory motion given by equation (1) and represented in Figure 2:

$x(t)=x_{o} e^{-\beta t} \cos (w t+\varphi)$

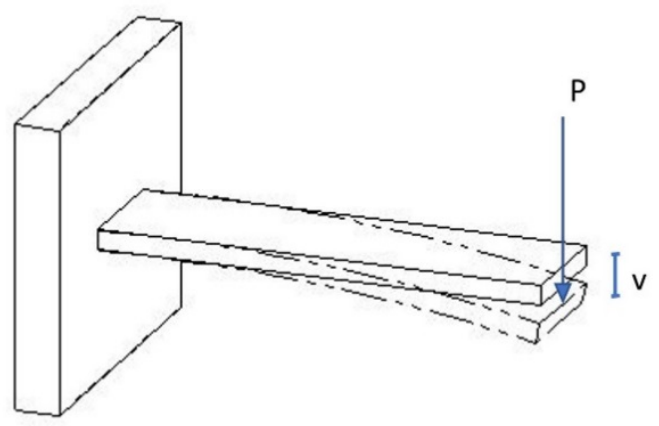

Fig.1: Loading of a sample

With $\mathrm{x}(\mathrm{t})$ the vertical displacement of the beam; $x_{o}$ the initial vertical displacement; $\beta$ the damping factor; $\omega$ the angular velocity and $\varphi$ the phase constant. [14]

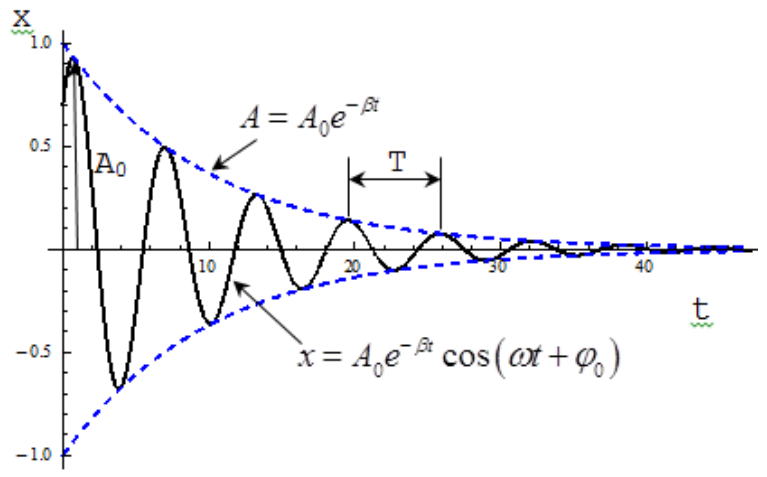

Fig. 2: Response of a damped oscillator
The logarithmic decrement $\delta$ is a measure of how fast the amplitude of the response decreases and is given by equation (2):

$$
\delta=\ln \frac{x n}{x n+1}
$$

The logarithmic decrement and the damping factor are linked by equation (3)

$$
\beta=\frac{\delta}{T}
$$

with $\mathrm{T}$ the period of the oscillation obtained by the inverse of the frequency

$$
T=\frac{2 \pi}{w}
$$

The damping ratio $\xi$ is given by the expression

$$
\xi=\frac{\beta}{2 \pi}
$$

The frequency-dependent elastic modulus is given by equation (5):

$$
E=\frac{4 \pi^{2}}{3 I_{z}} m f^{2} L^{3}
$$

where $m$ is the mass of the beam, $f$ the frequency, $L$ the beam's free length, $I_{z}$ the mass moment of inertia with respect to the axis perpendicular to the load. In the case of a static load $\mathrm{P}$, and substituting the geometric parameters of the section in Figure 3 we obtain:

$$
E=\frac{4 P}{W t 3}\left(1-v^{2}\right) L^{3}
$$

with $v$ the Poisson ratio and $\mathrm{W}$ the width.

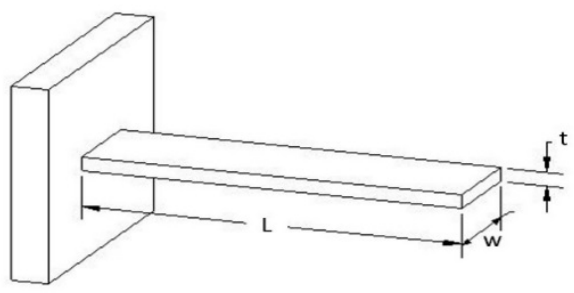

Fig. 3: Dimensions of the beam's section

The maximum deflection in the case of a static load $\mathrm{P}$ at the free end of a cantilever beam is shown in Figure 4 below. 
TABLE I

PHYSICAL CHARACTERISTICS OF SAMPLES

\begin{tabular}{|l|l|l|l|l|}
\hline & Alum & \multicolumn{1}{|c|}{ Steel } & \multicolumn{1}{c|}{ Oak } & Pine \\
\hline $\begin{array}{l}\text { Dimensions } \\
\text { (W x L x t } \\
\text { in mm) }\end{array}$ & $\begin{array}{l}19.1 \mathrm{x} \\
\text { (2x914.4 }\end{array}$ & $\begin{array}{l}20.3 \times 3.1 \times \\
914.4\end{array}$ & $33.6 \times 5.3 \times 914.4$ & $36.8 \times 5.3 \times 914.4$ \\
\hline $\begin{array}{l}\text { Density } \\
\text { (kg/m3) }\end{array}$ & 2.65 & 7.85 & 0.68 & 0.47 \\
\hline
\end{tabular}

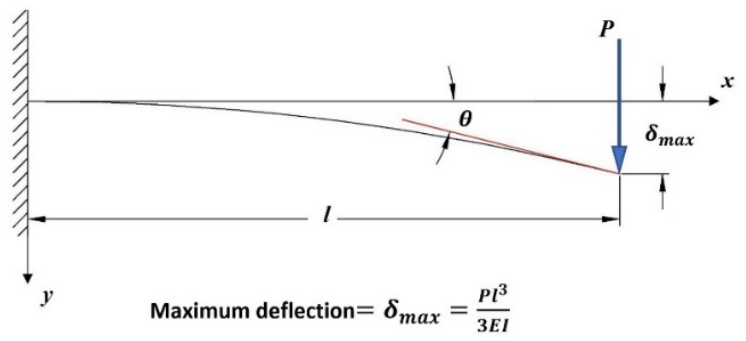

Fig.4: Deflection of Cantilever Beams

\section{EXPERIMENTAL SETUP}

\section{A. Mechanical Setup}

Four individual single layers material were used for the study. The dimensions of the specimens are included in Table I. In addition to single layers, the combination of steel and aluminum as well as pine with oak were obtained by gluing two single layers specimens. A single combination of layers was treated as a different specimen depending on the material forming the top or the bottom layer. In the study, steel over aluminum and aluminum over steel were considered as two different specimens when determining the dynamic response. Consequently, eight specimens were considered in the study. Four individual layers and four double-layers combinations. As shown in Figure 5, the specimens were clamped on one end to simulate totally fixed boundary conditions. Four accelerometers were used (two at the top and two at the bottom) to acquire data. A weight was suspended on the free end of the sample and released after a few seconds. The response was then recorded and processed using Python.
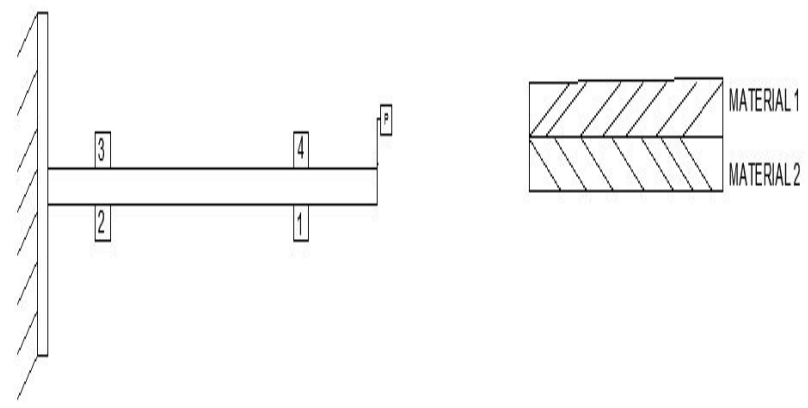

Fig.5: Experimental set-up for the measurement with layers arrangement

\section{B. Electronic setup and data acquisition}

The setting includes a Raspberry Pi system running at 1.2 GHz. Currently, acceleration samples can be obtained at a rate of $\sim 1 \mathrm{~ms}$ per sample. Each sample has three components $\left\{\mathrm{a}_{\mathrm{x}}, \mathrm{a}_{\mathrm{y}}, \mathrm{a}_{\mathrm{z}}\right\}$ values. The units are in g's $(g=$ $9.8 \frac{m}{s^{2}}$ ). The system is set to collect samples from up to 4 different location in the composite material (in this case, 4 pseudo-simultaneous samples are taken).

A prototype was built to avoid recalibrations of the sensors and to increase noise immunity.. The prototype was designed to provide data gathered from 8 accelerometers (3D) simultaneously along with 8 gyroscopes (3D) simultaneously. The current design allows for $1 \mathrm{kHz}$ sampling of any type of data (stream of a single parameter or a combination of various parameters (e.g., acc_x, acc_y, acc_z, gyr_x, gyr_y, gyr_z; in any order or combination).

The sensor connectors are spaced out, just in case it is necessary to add SPI interface to one of the sensor for faster acquisition speed (single channel to the Raspberry Pi). Internally, the sensor's I2C runs at $100 \mathrm{KHz}-400 \mathrm{KHz}$ providing an actual throughput of $\sim \frac{16 \mathrm{bits}}{1 \mathrm{~ms}}=\frac{1 \mathrm{word}}{1 \mathrm{~ms}}$ up to $\sim \frac{4 \text { words }}{1 \mathrm{~ms}}$. The internal SPI interface data-bus is designed to run at $1 \mathrm{MHz}-20 \mathrm{MHz}$ providing a potential high throughput, however, the limitation here is the speed of the sensor themselves. Another issue is that SPI would work up to 10 inches.

Figure 6 shows the final test bench and the prototype during last verification and integration.

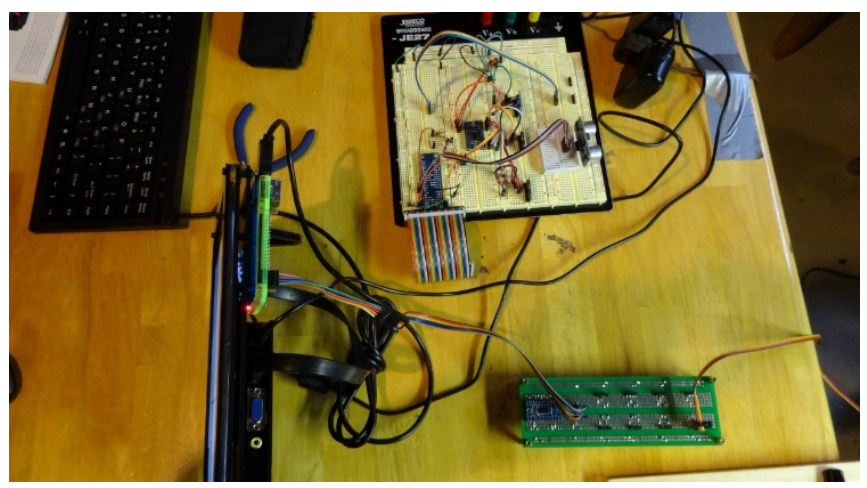

Fig. 6: Test-bench and Prototype Acquisition Board under Test

\section{Pre-processing and post-processing}

Before proceeding to gathering data, a number of software tests and procedure sequences were considered to obtain the best data measurements. The adopted procedure was as follows:

1) Choose the load and specimen on the test area.

2) Choose the number of sensors and location of sensors on the specimen.

3) Estimate the test period

4) Initialize the electronic system and calibrate the sensors. 
5) Remotely activate all accelerometers and gyroscopes along the specimen.

6) Set up the load and wait 2-3 seconds before releasing the load.

7) Stop the data acquisition system

8) Run Mathematica (with and/or without Kalman filter) to visually verify the validity of the test.

9) Upload data to desktop computer and execute post-processing algorithms in MATLAB.

Sensors calibration, in step 4 above, included the offline testing of biasing and the parametrization of noise characteristics of the sensors for the given data acquisition system. This information is used in the post-processing algorithms.

As mentioned in step 8, it is of great importance to be able to visualize the raw data for each experiment right after data was gathered. The current implementation uses Mathematica (included in the Raspberry Pi system) to find out if there are possible instrumentation problems in the system setting and if re-running the current experiment is needed. Step 8 could be enhanced to include preprocessing filtering (taking advantage of several Mathematica's signal processing features) and further analysis.

During the initial testing, we noticed that when the specimen was at rest, the accelerometers' data included some noise. Data obtained from the accelerometers, at-rest measurements; show that the accelerometers had a Gaussian noise component of about $\pm 2 \% \mathrm{~g} \Leftrightarrow$ $\sim 0.2 \frac{\mathrm{m}}{\mathrm{s}^{2}}$ when at rest.

Two percent error in the accelerometers might not be very significant; however, the post-processing filter gets rid of a significant portion of the Gaussian noise shown above. The post-processing implementation includes this filter as optional in the regular algorithm.

The current system is running using Python language for gathering information and Mathematica and MATLAB for pre- and post-processing. A possible update (in progress for the future) is to implement the gathering portion in LabVIEW via .vi files and using the Raspberry $\mathrm{Pi}$ as the interface agent.

The accelerometer information was processed with MATLAB. Raspberry Pi comes installed with Mathematica, but it does not have MATLAB installed. However, using the Wi-Fi and a program such as WinSCP (freeware), one can immediately transfer the data files to laptop and execute MATLAB functions.

\section{RESULTS}

\section{A. Localized Damping}

A typical variation of the damping factor at a point is shown in figure 7 in the case of steel computed with data recorded from sensor 1. It is worth noting that the damping varies at a single point. In this case, the damping factor varies from $\beta=0.3776$ to 0.3127 or a change of $17 \%$. The reported average value is $\beta=0.34$ ( $\xi=0.05$ ) for the single layer steel at location 1 , accounting for the entire recording period. In the literature, averaging three consecutive peaks, Patsias et al. [15] reached similar results. Throughout the text, we will present the recorded dynamic responses and the averaged value of the computed damping.

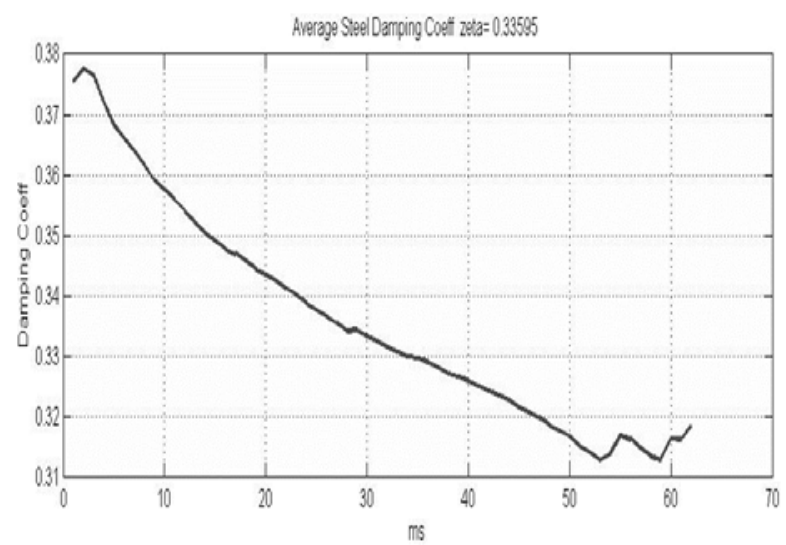

Fig. 7: Typical damping factor variation at a point

\section{B. Single Layers}

Recorded single layers responses are shown in Figures 8 and 9, for aluminum and steel, respectively. The responses are a measure of the acceleration along the vertical axis (z-axis) expressed as a factor of the gravity g. The decaying rate of the dynamic response is a measure of the damping ratio of the given material. A summary of the resulting damping ratios and elastic moduli computed are in Table II. A faster decay of the dynamic response indicates a higher damping ratio for the material. A lower decay or a more flat response indicates a much lower damping ratio of the sample in consideration. It takes much longer for the vibration to die for this later kind of materials. The results indicate a higher damping ratio for the oak followed by the pine, the aluminum and then the steel. The material with the highest density has the lowest damping. The same observation is valid when considering the Elastic moduli (E) values. The higher the values of E, the lower the damping factor.

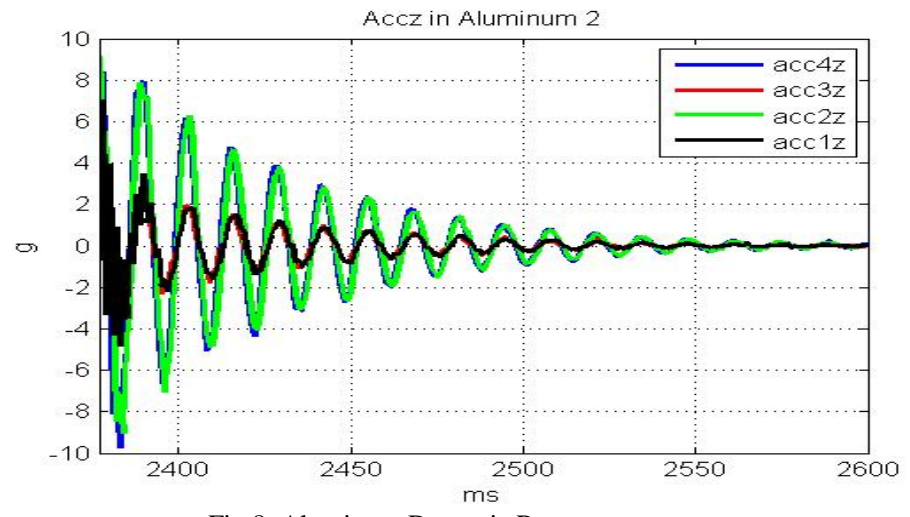

Fig 8. Aluminum Dynamic Response

$17^{\text {th }}$ LACCEI International Multi-Conference for Engineering, Education, and Technology: "Industry, Innovation, And Infrastructure for Sustainable Cities and Communities", 24-26 July 2019, Jamaica. 


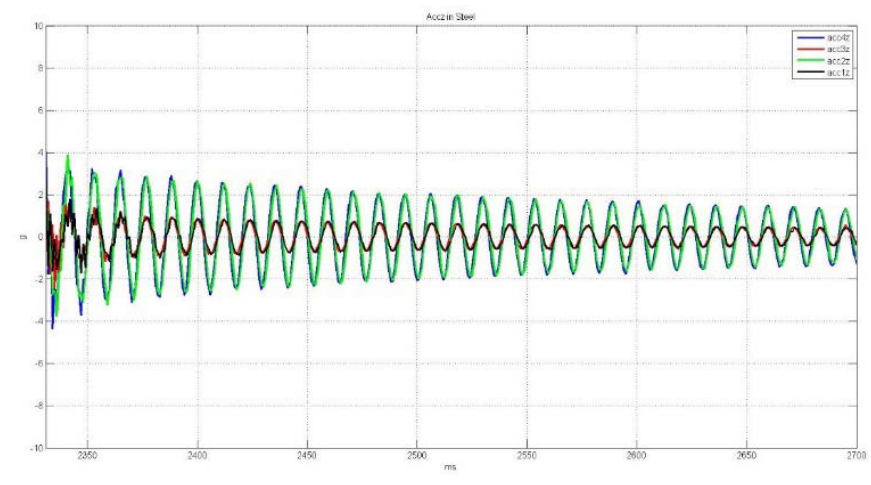

Fig 9. Steel Dynamic Response

TABLE II

SINGLE LAYER RESPONSE CHARACTERISTICS

\begin{tabular}{|l|l|l|l|}
\hline & E (GPa) & $\begin{array}{l}\text { Frequency } \\
(\mathrm{Hz})\end{array}$ & $\begin{array}{l}\text { Damping } \\
\text { factor } \beta(\xi)\end{array}$ \\
\hline Pine & 8.43 & 22.14 & $2.682(0.43)$ \\
\hline Oak & 7.96 & 21.48 & $4.672(0.74)$ \\
\hline Aluminum & 16.47 & 10.93 & $2.63(0.42)$ \\
\hline Steel & 38.39 & 12.51 & $0.34(0.05)$ \\
\hline
\end{tabular}

\section{Double-layers Material}

Figure 10 shows the dynamic responses in cases of layered systems. In these cases also, the responses are a measure of the acceleration along the vertical axis (z-axis) expressed as a factor of the gravity g. Computed values of damping factors and elastic moduli are shown in Table III. The results indicate a higher damping factor for the oak over pine combination, and a lower recorded value for the combination of steel over aluminum. The resulting value of the layered combination depends on the layers arrangements with the overall damping depending of the material of the top layer.
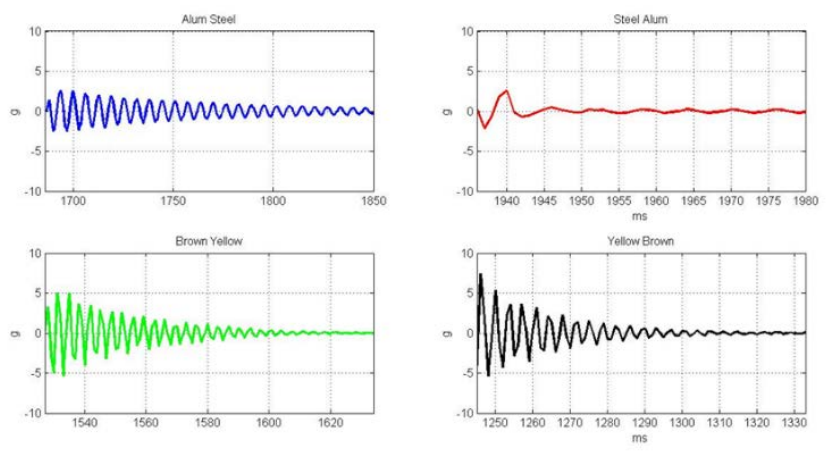

Fig. 10. Dynamic Response from all layered combinations: Top row: Aluminum over Steel and Steel over Aluminum. Bottom row: Oak over Pine and Pine over Oak
TABLE III LAYERED RESPONSE CHARACTERISTICS

\begin{tabular}{|c|c|c|c|}
\hline & E (GPa) & $\begin{array}{c}\text { Frequency } \\
(\mathrm{Hz})\end{array}$ & $\begin{array}{c}\text { Damping } \\
\text { factor } \beta(\xi)\end{array}$ \\
\hline $\begin{array}{c}\text { Pine over } \\
\text { Oak }\end{array}$ & 2.68 & 35.27 & $6.24(0.99)$ \\
\hline $\begin{array}{c}\text { Oak over } \\
\text { Pine }\end{array}$ & 5.21 & 49.17 & $4.91(0.78)$ \\
\hline $\begin{array}{c}\text { Alum over } \\
\text { Steel }\end{array}$ & 19.46 & 25.19 & $1.86(0.30)$ \\
\hline $\begin{array}{c}\text { Steel over } \\
\text { Alum }\end{array}$ & 16.06 & 23.44 & $1.31(0.21)$ \\
\hline
\end{tabular}

\section{DISCUSSION}

Under the loading and the boundary conditions used in the experiment, substantial variation of the damping occurs at single points due to cyclic loading (typically $17 \%$ ) and along the samples' lengths (from Point 4 to Point 3 and from Point 2 to Point 1). There is little variation of the amplitude of the response along the thickness of the samples. In single layers configuration, the highest damping factor occurs with the oak. The computed value is $\beta=4.67$. The pine, the aluminum and the steel follow it.

The higher the density, or the more compact the material, the lower the damping factor and the lower the energy lost in the vibration of molecules. High damping values, source of high-energy dissipation, will be useful in applications such as acoustic isolation where there will be a need for a sharp decrease in the response. On the other hand, low-damping materials such as steel $(\beta=0.34)$ can absorb more energy while releasing little. This kind of material is useful where no sharp decrease of the response to vibration is needed. The low-damping materials will perform better in cyclic and vibrational loads because they will resist better to these repetitive loads.

When examining the layered configurations, the top layer dominates the overall response. In a combination of steel and aluminum, the lowest damping factor value $(\beta=$ 1.31 ) is recorded with the steel overlaying the aluminum. The same type of response is observed when the oak layer is on top of the pine layer $(\beta=4.91)$. The overall response is not symmetrical because the top layer fibers are subjected to tension while the bottom later fibers are subjected to compression in the loading configuration used during the experiments. The stress and the ensuing deformation of the material are dependent upon the mechanical properties of the combined layers of material.

\section{CONCLUSION}

Damping of material is a complex dynamic property and its value is critical in predicting the response to dynamic loading and to controlling the response. While much work has been carried out to determine the exact value of the damping factor, the present work has discussed the variation of damping at a single location, through the

$17^{\text {th }}$ LACCEI International Multi-Conference for Engineering, Education, and Technology: "Industry, Innovation, And Infrastructure for Sustainable Cities and Communities", 24-26 July 2019, Jamaica. 
length of samples and their depths. It is worth noting that the damping ratio of a material under cyclic loading is a varying quantity (typically 17\%) and values reported in the literature are averages. The study has reported more variation along the lengths of sample(x-direction) and little variation along the z-axis on all the examined samples. On layered structures, the layers arrangements have yielded different values of damping coefficients. The overall damping of a layered media is governed by damping of the overlaying material of the top layer. Based on the desired outcome, consequent arrangements of the layers must be made to produce the needed damping of the layered combination.

\section{REFERENCES}

[1] Tita V, Jonas de Carvalho and Lirani, J. (2001), "A Procedure to Estimate the Dynamic Damped Behavior of Fiber Reinforced Composite Beams Submitted to Flexural Vibrations”, Material Research, Vol.4, No. 4, pp 315-321.

[2] Baidyia et al. (2006), "Investigation of Foundation Vibrations Resting on a Layered Soil System”, J. Geotech. Geoenviron. Eng., 2006, 132(1): 116-123

[3] Sandoval, L. and De Paula Franca, I. (2011), "Shocks in financial markets, Price expectation, and Damped harmonic oscillators",

[4] [Koblar, D. and Boltezar, M. (2016), "Evaluation of the FrequencyDependent Young Modulus and Damping Factor of Rubber from Experiment and Their Implementation in Finite Element Analysis", Experimental Techniques, Vol 40, Issue 1, pp 235-244
[5] Ladino, L.A and Rondón, S.H. (2017), "Determining the Damping Coefficient of a simple pendulum oscillating in air", Phys. Educ. 52 033007

[6] Moreira, R.A.S and Rodrigues, J.D "Multilayer Damping Treatments: Modeling and Experimental Assessment”, Journal of Sandwich Structures and Material, Vol. 12-March 2010

[7] Oberst, H., (1952), "Über die Dämpfung der Biegeschwingungen Dünner Bleche Durch Fest Haftende Belage,” J. Acustica, 2(4), pp. 181-194

[8] [Koruk, H and Sanliturk, K.Y (2010), ”On Measuring Dynamic Properties of Damping Materials Using Oberst Beam Method", Proceedings of the ASME 10th Biennial Conference, ESDA, Istanbul, Turkey.

[9] ASTM E 7056-05 standard (2005), "Standard Test Method for Measuring Vibration-Damping Properties of Materials”, American Society for Testing and Materials.

[10] Erdogan, G., Bayraktar, F., and Sanliturk, K.Y. (2003), "Measurement of Dynamic Properties of Materials", Inter.Noise 2003, Seogwipo, Korea, August 2003

[11] Maia, N.M.M, Lage, Y, E and Neves, M. M. (2012), "Recent Advances on Force Identification in Structural Dynamics", Adv. in Vibration Engineering and Structural Dynamics, INTECH, Ch.6

[12] Lin, R.L, Farag N.H, and Pan J, (2005), "Evaluation of the frequency dependent rubber mount stiffness and damping by impact test”, Applied Acoustics, 66, 829-844

[13] Ciornei, M., Diaconescu, E. and Glovnea, M. (2009), "Experimental Investigation of Wood Damping and Elastic Modulus”, DOCT-US, an. I, nr. 1.

[14] [Hibbeler, R.C., (2016), “Engineering Mechanics-Dynamics”, 14th ed., Pearson Prentice Hall, Hoboken, New Jersey.

[15] Patsias, S., Saxton, C. and Shipton, M. (2004),"Hard damping coatings: an experimental procedure for extraction of damping characteristics and modulus of elasticity”, Materials Science and Engineering A 370 (2004) 412-416

$17^{\text {th }}$ LACCEI International Multi-Conference for Engineering, Education, and Technology: "Industry, Innovation, And Infrastructure for Sustainable Cities and Communities”, 24-26 July 2019, Jamaica. 